\title{
Effect of Postural Drainage and Effective Cough After Nebulizer Intervention to in Oxygen Saturation Among Children with Bronchopneumonia
}

\author{
Selly Amelia Suryana Putri ${ }^{1}$, Lisbet Octavia Manalu ${ }^{1}$, Budi Somantri ${ }^{1}$, Albert \\ Manggading Hutapea ${ }^{2}$ \\ Sekolah Tinggi Ilmu Kesehatan Rajawali ${ }^{1}$ \\ Universitas Advent Indonesia ${ }^{2}$
}

\begin{abstract}
Bronchopneumonia is a disease that occurs at the distal end of the bronchioles, where this portion of the bronchiole is blocked by mucopurulent exudate. One of the main problems of children with bronchopneumonia is an increase in excessive sputum secretion that will affect the process of oxygen exchange, which ultimately can reduce the oxygen saturation in the blood of the patients. The purpose of this study was to determine the differences between postural drainage and effective cough exercises in nebulizer intervention on oxygen saturation changes in children aged 3-5 years with bronchopneumonia. Analytical quasi-experimental study design with preand post-test approach among 30 children in a hospital was utilized. Sampling was done with non-probability sampling technique. The methods used were postural drainage and effective cough. The result was analyzed using t-Test. The mean difference in oxygen saturation value in the postural drainage group was higher (4.53 $\%)$ than in the effective cough group (3.64\%). Result of unpaired t-Test indicated a p $=0.343$. Thus, there is no difference in postural drainage and effective cough exercises in nebulizer intervention to oxygen saturation change in bronchopneumonia. Future studies can be done on the effects of these methods when applied before nebulizer intervention.
\end{abstract}

Keywords: postural drainage, effective cough, bronchopneumonia 